\title{
A Combined Scanning Tunneling Microscopy and Electrochemical Study of Nickel Electrodeposition on $\boldsymbol{\beta}$-Brass
}

\author{
J. Morales, S. M. Krijer, P. Esparza, and S. González \\ Departamento de Química Física, Universidad de La Laguna, Tenerife, Spain \\ L. Vázquez \\ Instituto de Ciencia de Materiales, CSIC, Departamento de Física Aplicada, \\ C-XII, Universidad Autónoma de Madrid, 28049, Madrid, Spain \\ R. C. Salvarezza and A. J. Arvia \\ Instituto de Investigaciones Fisicoquímicas Teóricas y Aplicadas, \\ Sucursal 4, Casilla de Correo 16, 1900 La Plata, Argentina \\ Received July 14, 1995. In Final Form: October 26, $1995^{\otimes}$
}

\begin{abstract}
The electrodeposition of $\mathrm{Ni}$ on $\beta$-brass from Watt's bath was studied by using electrochemical techniques, scanning tunneling microscopy (STM) imaging, and X-ray diffraction. As the electrodeposition current density $j$ was increased from 0.01 to $0.25 \mathrm{~A} \mathrm{~cm}^{-2}$, both the $\mathrm{Ni}$ crystal size $(d)$ and the root mean square roughness of the deposit $(\xi)$ decreased. For $j>0.25 \mathrm{~A} \mathrm{~cm}^{-2}$ the deposit became rougher due to the growth of large Ni crystals over a background of small Ni crystals. This change in the growth mode appears as a transition in the value of $\xi$ which is promoted by strongly adsorbed intermediates involved in the discharge of $\mathrm{Ni}^{2+}$ ions. The analysis of the dynamic and static roughening exponents resulting from the application of the dynamic scaling theory to the STM images of Ni deposits indicates that the growth of Ni at high current density, i.e. far from the thermodynamic equilibrium, can be described as an aggregation process with a significant contribution of $\mathrm{Ni}$ atom surface diffusion.
\end{abstract}

\section{Introduction}

The electrodeposition of Ni on foreign substrates from different acid plating baths has been considered as a model system for establishing a correlation between the electrochemical parameters involved in the plating process and the Ni coating characteristics. ${ }^{1-8}$

The early stages of $\mathrm{Ni}$ electrodeposition on a foreign substrate have been modeled as a nucleation and threedimensional (3D) growth under charge transfer control ${ }^{1}$ involving either circular cones or hemispherical centers. ${ }^{2}$ As the amount of Ni increases, the coalescence of nuclei and other processes takes place, determining the texture and properties of thick deposits. ${ }^{3}$ In fact, Ni electrodeposition is accompanied by hydrogen evolution, a process which influences $\mathrm{Ni}$ electrocrystallization itself, and depending on the extent of hydrogen incorporation into the deposit, the ductility and internal stress of Ni coatings are considerably modified. ${ }^{4}$ Thus, hydrogen codeposition in a number of cases leads to the formation of a $\beta-\mathrm{Ni}$ hydride which is unstable at room temperature. ${ }^{5,6}$ However, the extent of $\beta$-Ni hydride formation and the amount of $\mathrm{H}$ trapped into the $\mathrm{Ni}$ deposit depend on both the

\footnotetext{
${ }^{\otimes}$ Abstract published in Advance ACS Abstracts, February 1, 1996.

(1) Proceedings of the Symposium on Electrocrystallization; Weil, R., Ed.; The Electrochemical Society: Pennington, 1981; Vol. 81-6.

(2) Abyaneh, M.; Fleischmann, M. J. Electroanal. Chem. Interfacial Electrochem. 1981, 187, 197.

(3) Amblard, J.; Froment, M.; Mauri, G.; Spyrellis, N.; TrevisanSouteyrand, E. Electrochim. Acta 1983, 28, 909.

(4) Armyanov, S.; Sotirova-Chakarova, G. J. Electrochem. Soc. 1992, $139,3454$.

(5) Tomov, I.; Monev, M. J. Appl. Electrochem. 1992, 22, 262.

(6) Tomov, I.; Monev, M.; Mikhailov, M.; Rashkov, S. J. Appl. Electrochem. 1992, 22, 82.

(7) Watson, S. W. J. Electrochem. Soc. 1993, 140, 2235.

(8) Arkan, C.; Bouet, V.; Gabrielli, C.; Maurin, G.; Perrot, H. J. Electrochem. Soc. 1994, 141, L103.
}

crystallographic plane of $\mathrm{Ni}$ and the density of defects in the electrodeposited phase such as crystal boundaries. ${ }^{7,8}$

The morphology of $\mathrm{Ni}$ electrodeposits from acid baths has been extensively studied by transmission electron microscopy and scanning electron microscopy on the $\mu \mathrm{m}$ scale, whereas only scarce information has been obtained from scanning tunneling microscopy (STM) and atomic force microscopy (AFM). These new techniques provide real 3D images of solid surfaces at a greater resolution. In fact, the application of nanoscopies to the study of metal deposits allowed us to advance in the quantitative interpretation of surface roughness development and its dependence on sample size ${ }^{9}$ from the analysis of STM and AFM images. This analysis raises the possibility of establishing the probable growth mechanism involved in $\mathrm{Ni}$ electrodeposition ${ }^{10}$ and the degree of surface disorder of the deposits. ${ }^{11}$

This work is devoted to study the influence of the rate of Ni electrodeposition from Watt's bath on $\beta$-brass on the surface roughness of $\mathrm{Ni}$ deposits. This study is based on data derived from electrochemical, ex situ STM, and X-ray diffraction techniques. Our results show that the increase in the Ni electrodeposition rate from 0.01 to $0.25 \mathrm{~A} \mathrm{~cm}^{-2}$ results in a decrease in the deposit crystal size and roughness and in an increase in surface disorder. For Ni electrodeposition rates greater than $0.25 \mathrm{~A} \mathrm{~cm}^{-2}$, large $\mathrm{Ni}$ crystals are formed, turning the deposit rougher. This morphology transition, which can be well-determined from the analysis of STM images, can be promoted by adsorbed intermediates such as strongly adsorbed hydrogen atoms appearing in the course of $\mathrm{Ni}^{2+}$ ion discharge. From the

(9) Salvarezza, R. C.; Arvia, A. J. Modern Aspects of Electrochemistry, Plenum Press: New York; Vol. 28, in press.

(10) Family, F. Physica A 1990, 168, 561 and references therein.

(11) Tong, W. M.; Stanley Williams, R.; Yanase, A.; Segawa, Y.; Anderson, M. S. Phys. Rev. Lett. 1994, 72, 3374. 
analysis of the dynamic and static roughening exponents derived from the application of the dynamic scaling to STM images, ${ }^{10}$ it can be concluded that Ni electrodeposits grown far from equilibrium conditions behave as self-affine fractals. The growth of these coatings can be described by growth models developed for aggregation processes incorporating surface diffusion. ${ }^{10}$

\section{Experimental Section}

$\mathrm{Ni}$ electrodeposits were made on a rotating disk $\beta$-brass $(60 \mathrm{Cu}-$ 40Zn) substrate $0.18 \mathrm{~cm}^{2}$ in apparent area at a rotation speed $\omega=1000 \mathrm{rpm}$, and a constant current density $(j)$ in the range $0.01 \mathrm{~A} \mathrm{~cm}^{-2}<j<0.5 \mathrm{~A} \mathrm{~cm}^{-2}$. A large Ni plate counter electrode and a saturated calomel reference electrode (SCE) were employed. The three electrodes were assembled in a glass-made electrochemical cell. The Watt's plating bath $\left(300 \mathrm{~g} / \mathrm{L} \mathrm{NiSO}_{4}, 50 \mathrm{~g} / \mathrm{L}\right.$ $\mathrm{NiCl}_{2}, 50 \mathrm{~g} / \mathrm{L} \mathrm{H}_{3} \mathrm{BO}_{3}, \mathrm{pH}=3.8$ ) at $60{ }^{\circ} \mathrm{C}$ was used.

STM imaging of Ni electrodeposits was made using Nanoscope III (Digital Instruments, Santa Barbara, CA) equipment operating in air using $\mathrm{Pt}-\mathrm{Ir}$ Nanotips. These tips assured a good reproducibility of the STM imaging. Images were taken in the topographic mode with a tunneling current in the range $1-5 \mathrm{nA}$, and bias voltage in the range $50-300 \mathrm{mV}$ with the tip negative. To minimize errors in the evaluation of the roughness exponents, STM images with $512 \times 512$ pixels were taken. ${ }^{9}$ STM data were analyzed after fitting the instrument plane and applying a subtracting procedure. ${ }^{12}$ The root mean square roughness $(\xi)$ defined in terms of the standard deviation of the surface height was measured from STM images using the specific STM software. ${ }^{12}$

The electrochemical characterization of $\mathrm{Ni}$ electrodeposits was made on the basis of conventional voltammetry and hydrogencharging experiments in $1 \mathrm{M} \mathrm{KOH}$. A conventional X-ray diffractometer was also used to characterize Ni electrodeposits.

\section{Results}

3.1. Electrochemical Data. The single potential sweep voltammogram for Ni electrodeposition from Watt's bath run at $0.005 \mathrm{~V} \mathrm{~s}^{-1}$ between $E_{\mathrm{a}}=-0.6 \mathrm{~V}$ and $E_{\mathrm{c}}=$ $-2.0 \mathrm{~V}$ (Figure 1a) behaves as a steady state polarization curve for Ni electrodeposition. It shows an exponential current increase in the range $-0.6 \mathrm{~V}>E>-0.9 \mathrm{~V}$. In this potential range, the $\log j$ vs $E$ plot yields a straight line with the cathodic Tafel slope $b_{\mathrm{c}} \cong 0.132 \mathrm{~V} /$ decade (Figure $1 \mathrm{~b}$ ). This value of $b_{\mathrm{c}}$ indicates that in the range $-0.6>E>-0.9 \mathrm{~V}$ the kinetics of the Ni electrodeposition reaction is probably controlled by the first charge transfer step. ${ }^{13}$

For $E<-1.0 \mathrm{~V}$, and in the range $0<\omega<4000 \mathrm{rpm}$, a linear increase in $j$ with $E$, irrespective of $\omega$, is found. In this case, $\mathrm{Ni}$ electrodeposition is accompanied by the simultaneous formation of hydrogen bubbles, and the overall process behaves as an electrochemical process under ohmic control.

The current efficiency (CE) for Ni electrodeposition was determined by comparing the weight of deposited Ni with the prediction of Faraday's law. Thus, values of $\mathrm{CE}$ resulted in $\mathrm{CE}=93.7 \pm 0.5 \%$ at $j=0.02 \mathrm{~A} \mathrm{~cm}^{-2}$, and $\mathrm{CE}$ $=95.6 \pm 0.5 \%$ at $j=0.4 \mathrm{~A} \mathrm{~cm}^{-2}$. The former figure is close to $94 \%$, a value reported in the literature for Watt's bath. ${ }^{14}$ From the weight of deposited $\mathrm{Ni}$, the values of $h$, the average deposit thickness, resulted in $h=170 \mu \mathrm{m}$ for $q$ $=551 \mathrm{C} \mathrm{cm}^{-2}$.

The hydrogen evolution reaction (HER) was studied on a Ni electrodeposit grown at $j=0.4 \mathrm{~A} \mathrm{~cm}^{-2}$ using a solution comparable to Watt's bath in which $\mathrm{Ni}^{2+}$ ions were replaced by $\mathrm{Na}^{+}$ions. The $j$ vs $E$ plots made at different values of

(12) Krim, J.; Heyvaert, I.; Van Haesendonck, C.; Bruynseraede, Y. Phys. Rev. Lett. 1993, 70, 57.

(13) Epelboin, I.; Wiart, R. J. Electrochem. Soc. 1971, 118, 1577.

(14) Nakahara, S.; Felder, E. C. J. Electrochem. Soc. 1982, 129, 45.

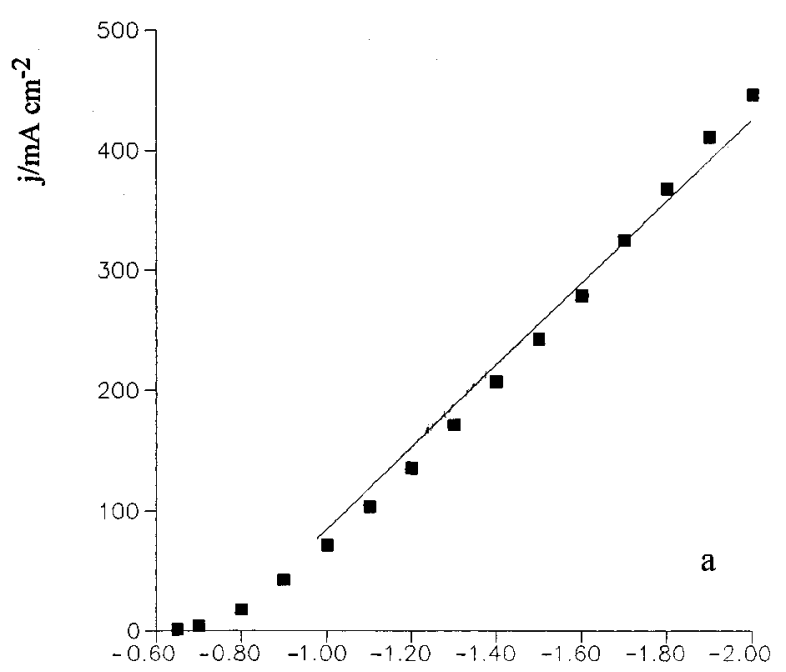

$\mathrm{E} / \mathrm{V}$

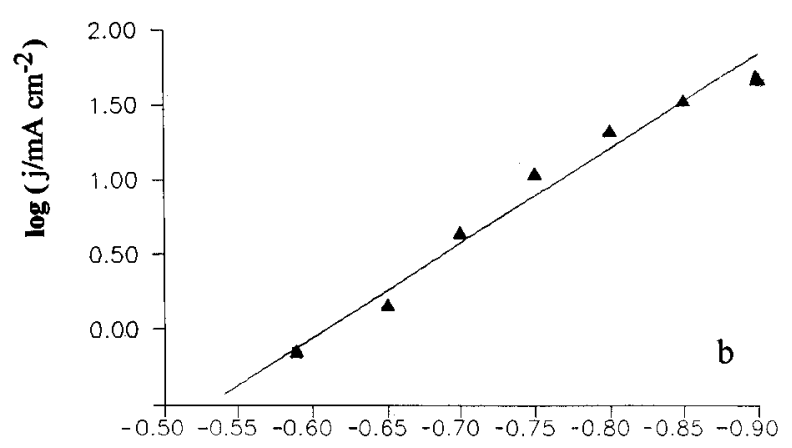

$\mathrm{E} / \mathrm{V}$

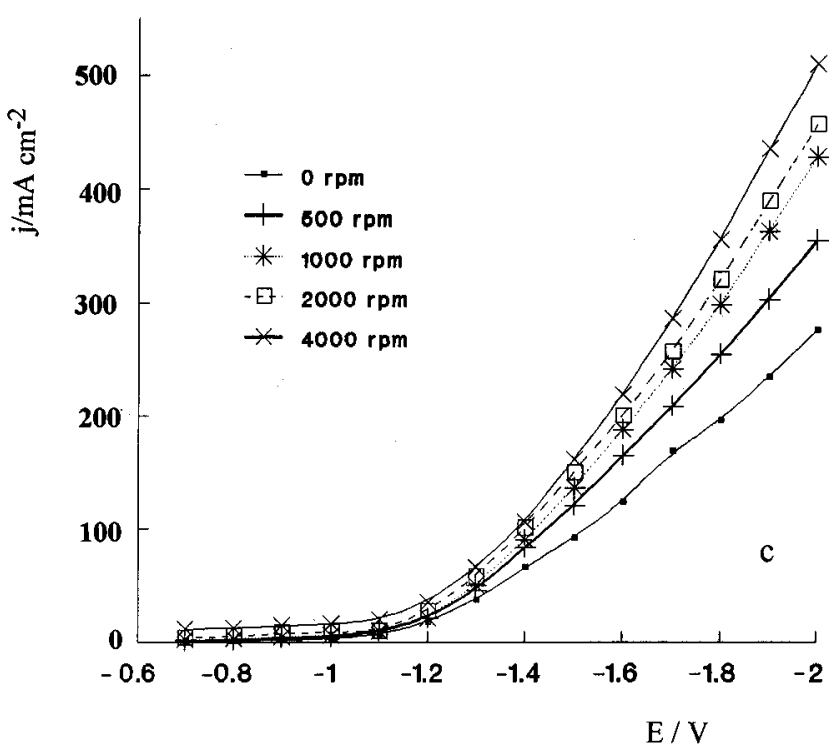

Figure 1. (a) $j$ vs $E$ plot for Ni electrodeposition from Watt's bath recorded at $0.005 \mathrm{~V} \mathrm{~s}^{-1}$ between $E_{\mathrm{a}}=-0.6 \mathrm{~V}$ and $E_{\mathrm{c}}=-2.0$ $\mathrm{V}$ : electrode rotation speed $1000 \mathrm{rpm}, T=60^{\circ} \mathrm{C}$. (b) $\log j \mathrm{vs}$ $\log E$ plot of the initial portion of the polarization curve shown in part a. (c) $j v s E$ plot for the hydrogen evolution reaction run at different values of $\omega$ on a Ni coating grown at $j=0.4 \mathrm{~A} \mathrm{~cm}^{-2}$ $\left(A_{\mathrm{f}}=3.7\right)$ using a solution comparable to Watt's bath in which $\mathrm{Ni}^{2+}$ ions were replaced by $\mathrm{Na}^{+}$ions.

$\omega$ are shown in Figure 1c. In the range $-0.7 \mathrm{~V} \leq E \leq-1.0$ $\mathrm{V}$ a limiting value of $j$ is approached. Its value increases with $\omega^{1 / 2}$ as it has been already reported. ${ }^{8}$ This fact is consistent with a HER kinetics under mass transport control of $\mathrm{H}^{+}$ions from the bulk of the solution to the 

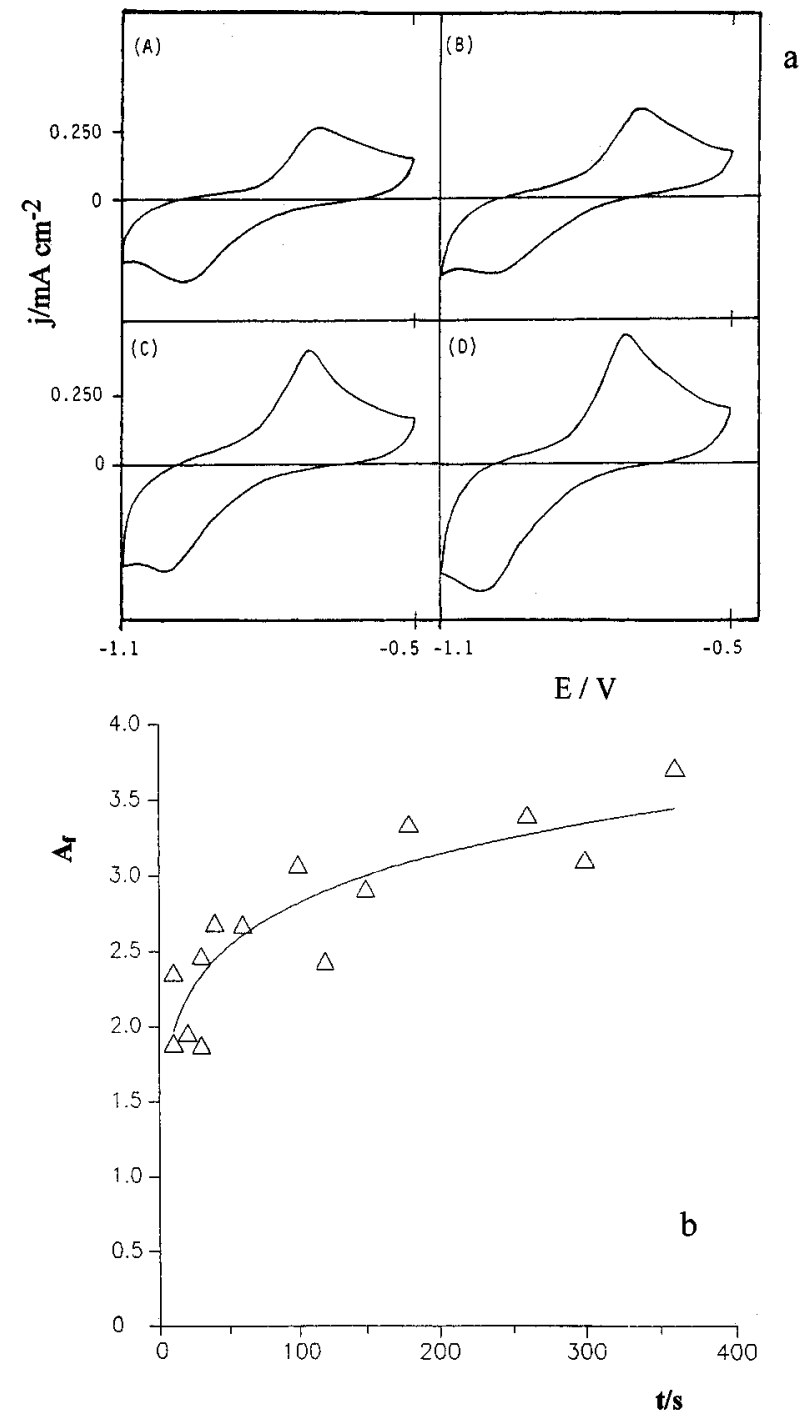

Figure 2. (a) Voltammograms of $\mathrm{Ni}$ electrodeposits run in 1 $\mathrm{M} \mathrm{KOH}$ at $V=0.05 \mathrm{~V} / \mathrm{s}$ between $E_{\mathrm{a}}=-0.5$ and $E_{\mathrm{c}}=-1.10 \mathrm{~V}$. $\mathrm{Ni}$ deposits were prepared at $j=0.3 \mathrm{~A} \mathrm{~cm}^{-2}$ and a different electrodeposition time $t$. (A) $t=10 \mathrm{~s}$, (B) $t=40 \mathrm{~s}$, (C) $t=260$ s, (D) $t=360 \mathrm{~s}$. (b) $A_{\mathrm{f}}$ vs $t$ plot, $A_{\mathrm{f}}$ data were derived from voltammograms shown in part a.

electrode surface. In contrast, for $E<1.0 \mathrm{~V}$ a remarkable increase in $j$ with $E$ can be noted, as would be expected for the HER proceeding from the discharge of water molecules. ${ }^{8}$ The increase in current with $\omega$ at a given potential observed in this region can be attributed to the progressive removal of hydrogen bubbles from the electrode surface as $\omega$ is increased.

The slight increase in the $\mathrm{CE}$ for Ni electrodeposition with $E$ can be explained considering that on increasing $E$ the electrodeposition of $\mathrm{Ni}$ is favored, as compared to the HER from the discharge of water molecules.

Single-sweep voltammograms of Ni deposits built up at $j=0.3 \mathrm{~A} \mathrm{~cm}^{-2}$, in the range of electrodeposition time $3 \mathrm{~s}$ $<t<400 \mathrm{~s}$, were run in $1 \mathrm{M} \mathrm{KOH}$ at $v=0.05 \mathrm{~V} / \mathrm{s}$, between $E_{\mathrm{a}}=-0.5 \mathrm{~V}$ and $E_{\mathrm{c}}=-1.10 \mathrm{~V}$ (Figure 2a). These voltammograms show current contributions related to the electroformation and electroreduction of the $\mathrm{Ni}(\mathrm{OH})_{2}$ monolayer, ${ }^{15}$ the anodic $\left(q_{\mathrm{a}}\right)$ and the cathodic $\left(q_{\mathrm{c}}\right)$ voltammetric charge densities referred to the substrate area being almost equal. Thus, using the value of $q_{\text {a }}$ from Figure $2 a$ and taking the charge density involved in the electroformation of the $\mathrm{Ni}(\mathrm{OH})_{2}$ monolayer, $q_{\mathrm{ML}}=0.5 \mathrm{mC}$

(15) Machado, A. S. S.; Avaca, L. A. Electrochim. Acta 1994, 10, 1385.

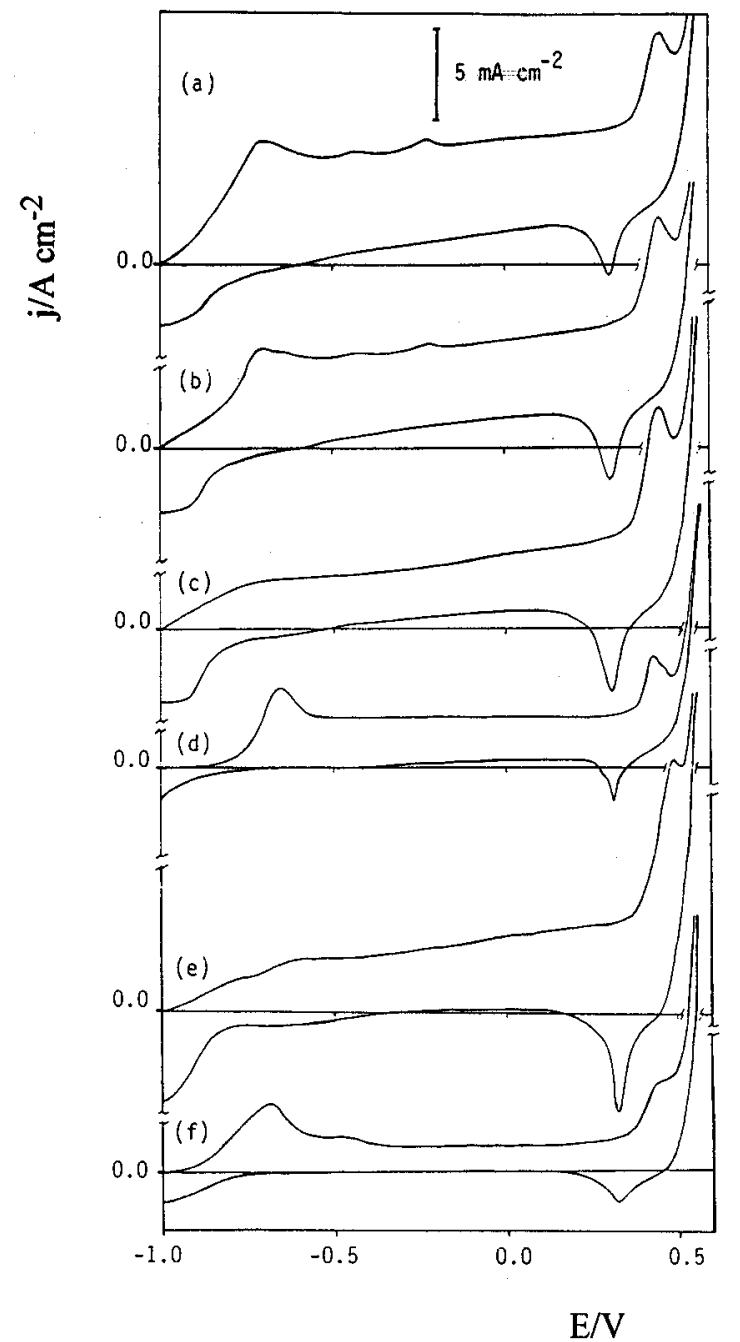

Figure 3. Voltammograms of $\mathrm{Ni}$ specimens run in $1 \mathrm{M} \mathrm{KOH}$ at $V=0.05 \mathrm{~V} / \mathrm{s}$ between $E_{\mathrm{a}}=-1.0$ and $E_{\mathrm{c}}=0.50 \mathrm{~V}$. Ni electrodeposits were previously cathodized for $5 \mathrm{~min}$ at a different value of $E_{\mathrm{c}}$ : (a) Ni electrodeposit made at $j=0.4 \mathrm{~A}$ $\mathrm{cm}^{-2}\left(q=551 \mathrm{C} \mathrm{cm}^{-2}\right), E_{\mathrm{c}}=-2.0 \mathrm{~V}$; (b) Ni electrodeposit made at $j=0.4 \mathrm{~A} \mathrm{~cm}^{-2}\left(q=551 \mathrm{C} \mathrm{cm}^{-2}\right), E_{\mathrm{c}}=-1.4 \mathrm{~V} ;$ (c) $\mathrm{Ni}$ electrodeposit made at $j=0.4 \mathrm{~A} \mathrm{~cm}^{-2}\left(q=551 \mathrm{C} \mathrm{cm}^{-2}\right), E_{\mathrm{c}}=$ $-1.0 \mathrm{~V}$; (d) Ni 99.99, $E_{\mathrm{c}}=-2.0 \mathrm{~V}$; (e) Ni electrodeposit made at $j=0.02 \mathrm{~A} \mathrm{~cm}^{-2}\left(q=551 \mathrm{C} \mathrm{cm}^{-2}\right), E_{\mathrm{c}}=-2 \mathrm{~V}$; (f) $\mathrm{Ni}$ electrodeposit made at $j=0.4 \mathrm{~A} \mathrm{~cm}^{-2}\left(\mathrm{q}=551 \mathrm{C} \mathrm{cm}^{-2}\right)$ and annealed for $t_{\mathrm{a}}=2 \mathrm{~h}, E_{\mathrm{c}}=-2.0 \mathrm{~V}$.

$\mathrm{cm}^{-2}, 15$ the deposit area-to-substrate area ratio $\left(A_{\mathrm{f}}\right)$ was estimated. The corresponding $A_{\mathrm{f}}$ vs $t$ plot (Figure 2b) indicates that as $t$ is increased, $A_{\mathrm{f}}$ also increases to reach a steady state value for $t>300 \mathrm{~s}$. This means that the $\mathrm{Ni}$ surface first becomes gradually rougher until it attains saturation roughness.

To gain information about the participation of hydrogen absorption in the growth mode of $\mathrm{Ni}$ electrodeposits, the influence of the topography of Ni deposits on the absorption of hydrogen by $\mathrm{Ni}$ was investigated. For this purpose electrodes consisting of either Ni electrodeposits $(q=551$ $\mathrm{C} \mathrm{cm}^{-2}$ ) made at $j=0.02$ and $0.4 \mathrm{~A} \mathrm{~cm}^{-2}$ or $\mathrm{Ni} 99.99 \%$ were used as substrates for hydrogen charging. All these electrodes were cathodized at $E_{\mathrm{c}}=-2.0,-1.4$, and -1.0 $\mathrm{V}$ for $5 \mathrm{~min}$ and then subjected to a voltammetric sweep between -1.0 and $0.6 \mathrm{~V}$ at $V=0.05 \mathrm{~V} \mathrm{~s}^{-1}$. For $\mathrm{Ni}$ electrodeposits grown at $j=0.4 \mathrm{~A} \mathrm{~cm}^{-2}$ and held at $E_{\mathrm{c}}=$ $-2.0 \mathrm{~V}$, single-sweep voltammograms showed a diffusional hydrogen electrooxidation current superimposed to $\mathrm{Ni}$ $(\mathrm{OH})_{2}$ and $\mathrm{NiOOH}$ electroformation (Figure $\left.3 \mathrm{a}\right)$. As $E_{\mathrm{c}}$ is moved positively, the magnitude of the hydrogen electrooxidation current decreases, and the charge involved 


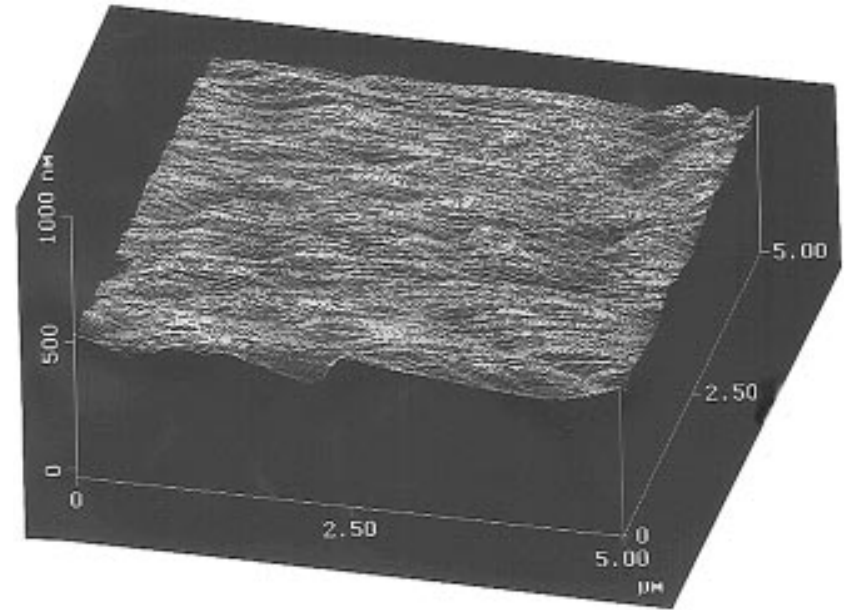

Figure 4. Three-dimensional STM image $\left(5 \times 5 \mu \mathrm{m}^{2}\right)$ of the $\beta$-brass substrate.

in those current peaks related to $\mathrm{Ni}(\mathrm{OH})_{2}$ and $\mathrm{NiOOH}$ electroformation increases (Figure $3 \mathrm{~b}, \mathrm{c}$ ). At the same $E_{\mathrm{c}}$, the contribution of the hydrogen electrooxidation current decreases in the following order: Ni electrodeposit $(j=$ $\left.0.4 \mathrm{~A} \mathrm{~cm}^{-2}\right)>\mathrm{Ni}$ electrodeposit $\left(j=0.02 \mathrm{~A} \mathrm{~cm}^{-2}\right)>\mathrm{Ni}$ 99.99\% (Figure 3a,d,e). Accordingly, there is a direct correlation between the amount of absorbed hydrogen and the current density used for Ni electrodeposition. The increase in hydrogen absorption can be related to either a change in the structure of the Ni deposit or an increase in the real surface area of the electrodeposit, or both occurring simultaneously. Thus, by repeating these experiments using $\mathrm{Ni}$ electrodeposits grown at $j=0.4 \mathrm{~A}$ $\mathrm{cm}^{-2}$ and subsequently annealing them in a vacuum at $180{ }^{\circ} \mathrm{C}$ for different times $\left(t_{\mathrm{a}}\right)$ (Figure $3 \mathrm{f}$ ), a remarkable decrease in the hydrogen electrooxidation current with $t_{\mathrm{a}}$ was observed. It should be noted that annealing results in a crystal growth which in turn decreases the contribution of crystal boundaries, the density of defects, and the surface area of the deposit. It should be noted that crystal boundaries and crystal defects become the preferred sites for the penetration of $\mathrm{H}$ into solid metals. 5,6

3.2. STM Imaging. Ex situ STM images of the $\beta$-brass substrate (Figure 4) show a relatively smooth surface formed by terraces and steps several atoms in height. For these surfaces the value of $\xi$ is in the range $2 \mathrm{~nm} \leq \xi \leq$ $8 \mathrm{~nm}$.

The Ni substrate topography resulting from a deposit produced after passing $q=551 \mathrm{C} \mathrm{cm}^{-2}$ is completely different from that of the substrate (Figures $5-7$ ). The topography of Ni coatings depends on the electrodeposition rate, i.e. on the value of $j$ used to grow the deposit. Thus, 3D STM images ( $5 \mu \mathrm{m} \times 5 \mu \mathrm{m}$ in size), resulting from $\mathrm{Ni}$ electrodeposits made at $j=0.05 \mathrm{~A} \mathrm{~cm}^{-2}$ (Figure 5a), exhibit large pyramidal crystals with a typical root mean square roughness $\xi \cong 160 \mathrm{~nm}$. This topography resembles the pyramidal growth which has been reported for Ni electrodeposited on Cu substrates from acid baths. ${ }^{3}$ The cross sections of the STM images at higher resolution $(2 \times 2$ $\mu \mathrm{m}^{2}$ in size) reveal smooth crystal surfaces (Figure $5 \mathrm{~b}$ ) although the central part of the terraces is at a lower level than the edges. The intersections of crystal edges form angles which are compatible with $\mathrm{Ni}(111)$ and $\mathrm{Ni}(100)$ crystal surfaces. From STM images the value of the average crystal size results in $d=0.7 \mu \mathrm{m}$, and the density of the crystal is $N=1.6 \times 10^{8} \mathrm{~cm}^{-2}$.

As $j$ is increased from 0.05 to $0.2 \mathrm{~A} \mathrm{~cm}^{-2}$, Ni pyramids become smaller and tend to overlap (Figure 6a). At which time, the minimum value $\xi=80 \mathrm{~nm}$ is attained. In this case, each pyramid surface involves a large density of
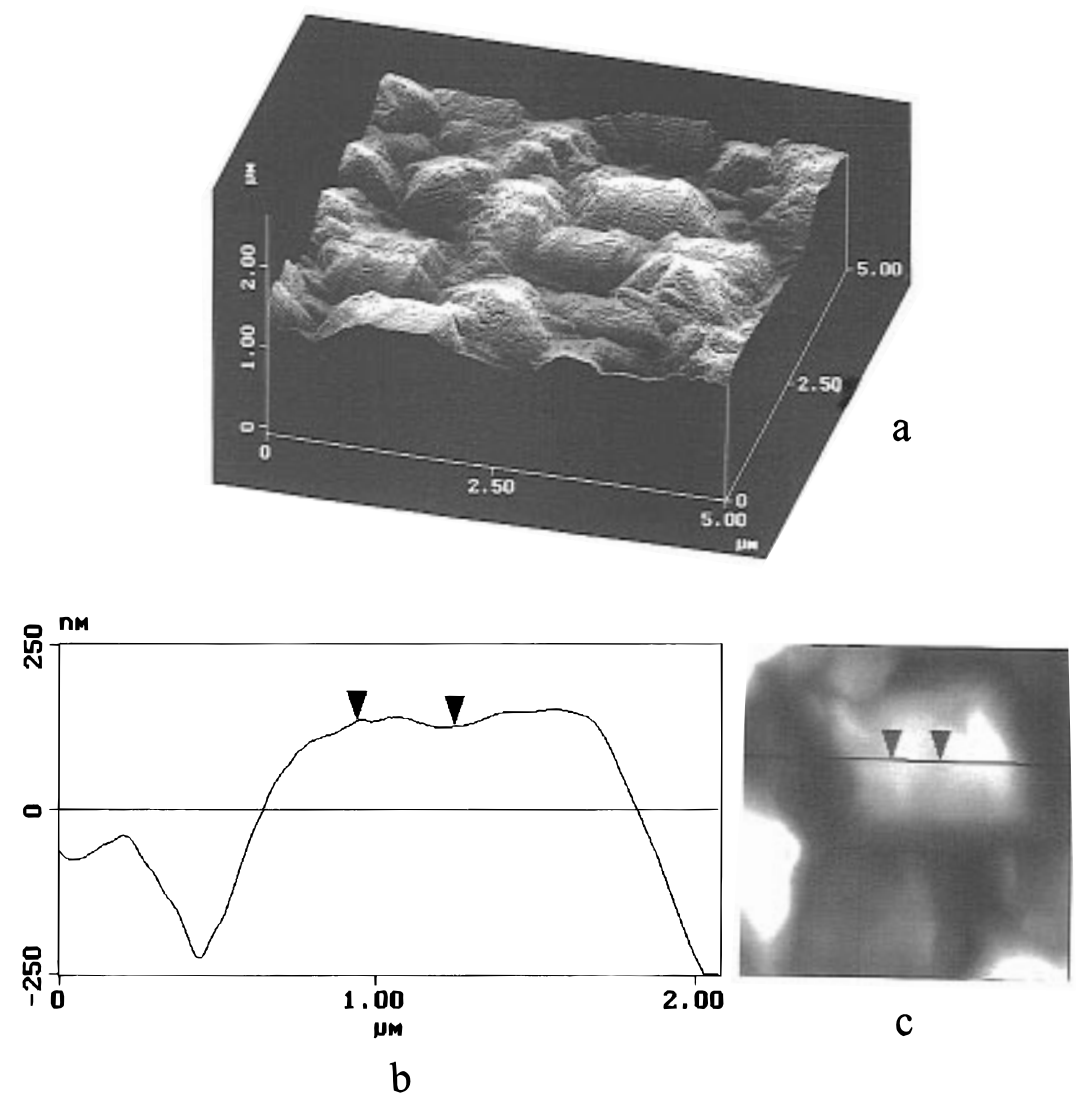

Figure 5. (a) Three-dimensional STM image $\left(5 \times 5 \mu \mathrm{m}^{2}\right)$ of a Ni electrodeposit grown at $j=0.05 \mathrm{~A} \mathrm{~cm}-2(q=551 \mathrm{C} \mathrm{cm}-2)$. (b) Cross section of a domain $\left(2 \times 2 \mu \mathrm{m}^{2}\right)$ of the STM image shown in part c. The STM image (2D) shown in part c corresponds to a domain of the 3D STM image depicted in part a. 

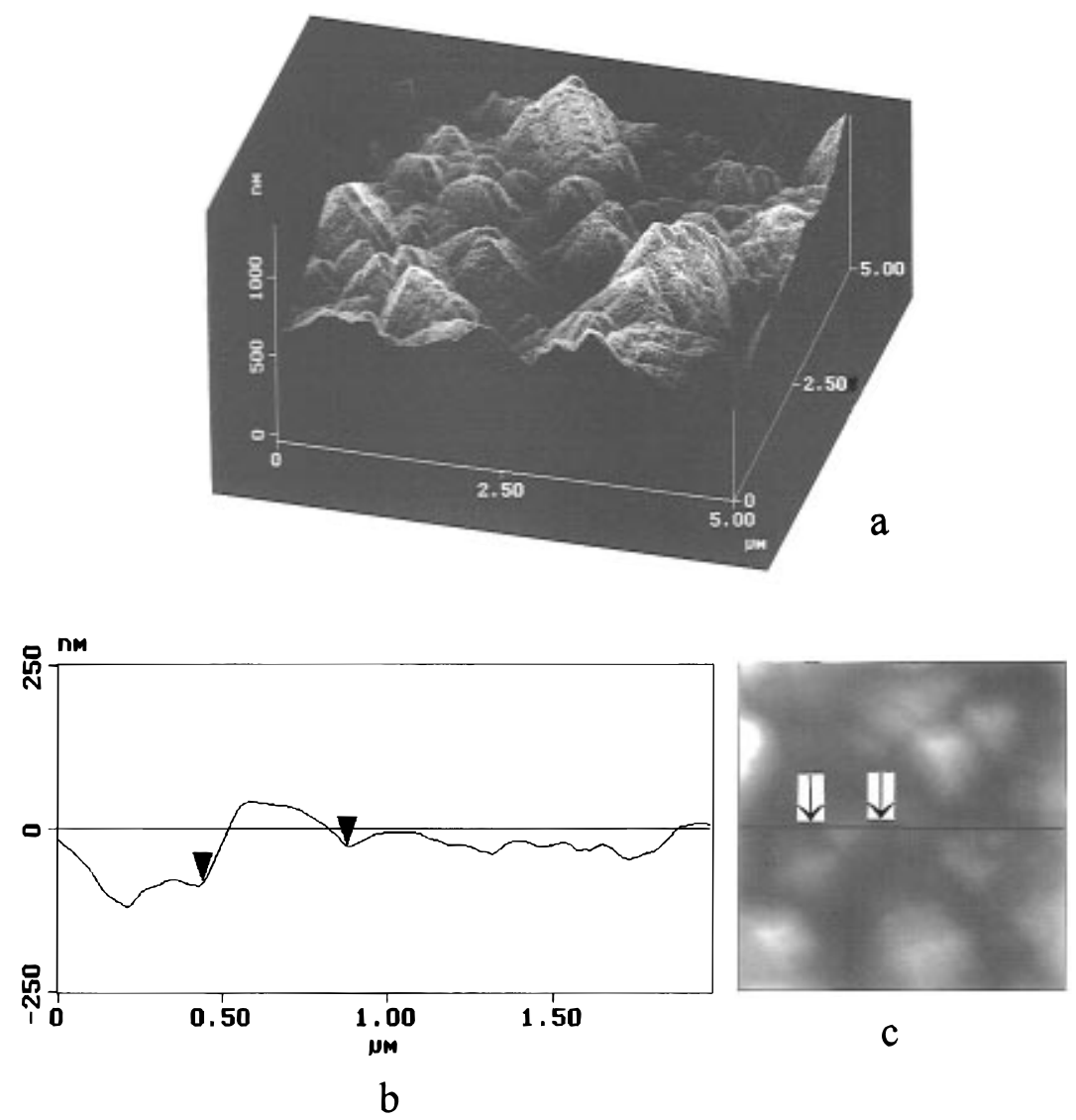

$\mathrm{b}$

Figure 6. (a) Three-dimensional STM image $\left(5 \times 5 \mu \mathrm{m}^{2}\right)$ of a Ni electrodeposit grown at $j=0.2 \mathrm{~A} \mathrm{~cm}-2\left(q=551 \mathrm{C} \mathrm{cm}^{-2}\right)$. (b) Cross section of a domain $\left(2 \times 2 \mu \mathrm{m}^{2}\right)$ of the STM image shown in part c. The STM image (2D) shown in part c corresponds to a domain of the 3D STM image depicted in part a.

steps and a decrease in the degree of order of the deposit due to height fluctuations among small pyramids (Figure $6 \mathrm{~b})$. Correspondingly, it results in $d=0.45 \mu \mathrm{m}$ and $N=$ $5 \times 10^{8} \mathrm{~cm}^{-2}$.

On the other hand, for $j>0.2 \mathrm{~A} \mathrm{~cm}^{-2}$, a heterogeneous $\mathrm{Ni}$ deposit consisting of small crystals $(d \cong 0.2 \mu \mathrm{m})$ and a small number of large crystals $(1 \mu \mathrm{m}<d<2 \mu \mathrm{m})$ is observed (Figure 7a). The appearance of large crystals abruptly increases the value of $\xi$ up to the limiting value $\xi=180 \mathrm{~nm}$. The morphological change just described can be related to a transition in the growth mode of $\mathrm{Ni}$ from a pyramid to a nodular morphology. This type of transition has been already reported for Ni electrodeposition from the same bath at high current densities. ${ }^{3}$ Furthermore, the surface of large crystals is somewhat disordered due to the high density of small bumps (Figure $7 b)$.

Therefore, results from STM imaging indicate that at a constant value of $j$ for this type of deposit there is a clear correlation between $d$ and $\xi$, as seen from the $\xi$ vs $j$ plot (Figure 8a) and $d$ vs $j$ plot (Figure $8 \mathrm{~b}$ ) over the entire range of $j$ covered in this work.

3.3. X-ray Diffractograms. X-ray diffractograms of Ni electrodeposits $\left(q=551 \mathrm{C} \mathrm{cm}^{-2}, h \cong 170 \mu \mathrm{m}\right)$ grown at either $j=0.02 \mathrm{~A} \mathrm{~cm}^{-2}$ or $j=0.4 \mathrm{~A} \mathrm{~cm}^{-2}$ exhibit only those diffraction lines of $\mathrm{Ni}(111)$ and $\mathrm{Ni}(200)$ (Figure 9) related to $\mathrm{Ni}$ crystallites oriented in the [111] and [100] pole direction, respectively. Unfortunately, as the diffractograms were made after $\mathrm{Ni}$ electrodeposition, the diffraction lines of the highly unstable $\beta$ - $\mathrm{NiH}$ cannot be observed.

On the other hand, X-ray diffractograms show the absence of $\mathrm{Cu}$ and $\mathrm{Zn}$ signals, as should occur for a substrate completely covered by a thick Ni electrodeposit.

\section{Discussion}

4.1. Reaction Kinetics and Growth Mode. The kinetics of $\mathrm{Ni}$ electrodeposition can be interpreted by the reaction mechanism proposed by Epelboin et al. ${ }^{16} \mathrm{Ac}$ cordingly, $\mathrm{Ni}$ and $\mathrm{H}_{2}$ codeposition reactions imply a series of steps,

$$
\begin{gathered}
2 \mathrm{H}^{+}+2 \mathrm{e}^{-} \Longrightarrow \mathrm{H}_{2} \\
2 \mathrm{H}_{2} \mathrm{O}+2 \mathrm{e}^{-} \Longrightarrow \mathrm{H}_{2}+2 \mathrm{OH}^{-} \\
\mathrm{Ni}^{2+}+\mathrm{e}^{-} \Longrightarrow \mathrm{Ni}_{\mathrm{ad}}^{+} \\
\mathrm{Ni}_{\mathrm{ad}}^{+}+\mathrm{e}^{-} \Longrightarrow \mathrm{Ni} \\
\mathrm{Ni}_{\mathrm{ad}}^{+}+\mathrm{Ni}^{2+}+2 \mathrm{e}^{-} \Longrightarrow \mathrm{Ni}+\mathrm{Ni}_{\mathrm{ad}}^{+} \\
\mathrm{Ni}_{\mathrm{ad}}^{+}+\mathrm{H}^{+}+\mathrm{e}^{-} \Longrightarrow \mathrm{Ni}_{\mathrm{ad}}^{+}+\mathrm{H}_{\mathrm{ad}} \\
\mathrm{Ni}_{\mathrm{ad}}^{+}+\mathrm{H}_{2} \mathrm{O}^{+} \mathrm{e}^{-} \mathrm{NiOH}_{\mathrm{ad}}+\mathrm{H}_{\mathrm{ad}} \\
2 \mathrm{H}_{\mathrm{ad}} \Longrightarrow \mathrm{H}_{2} \\
\mathrm{Ni}_{\mathrm{ad}}+\mathrm{H}_{\mathrm{ad}}+\mathrm{e}^{-} \Longrightarrow \mathrm{Ni}^{+} \mathrm{H}_{\mathrm{ab}}
\end{gathered}
$$

where ad and ab stand for adsorbed and absorbed species. Reaction 1a occurs in the range $-0.7 \mathrm{~V} \leq E \leq-1.0 \mathrm{~V}$, whereas reaction $1 \mathrm{~b}$ proceeds for $E<-1.0 \mathrm{~V} .{ }^{8}$ Reactions 2 and 4 are the most likely paths for $\mathrm{Ni}^{2+}$ ion electrore-

(16) Epelboin, I.; Joussellin, M.; Wiart, R. J. Electroanal. Chem. Interfacial Electrochem. 1981, 119, 61. 

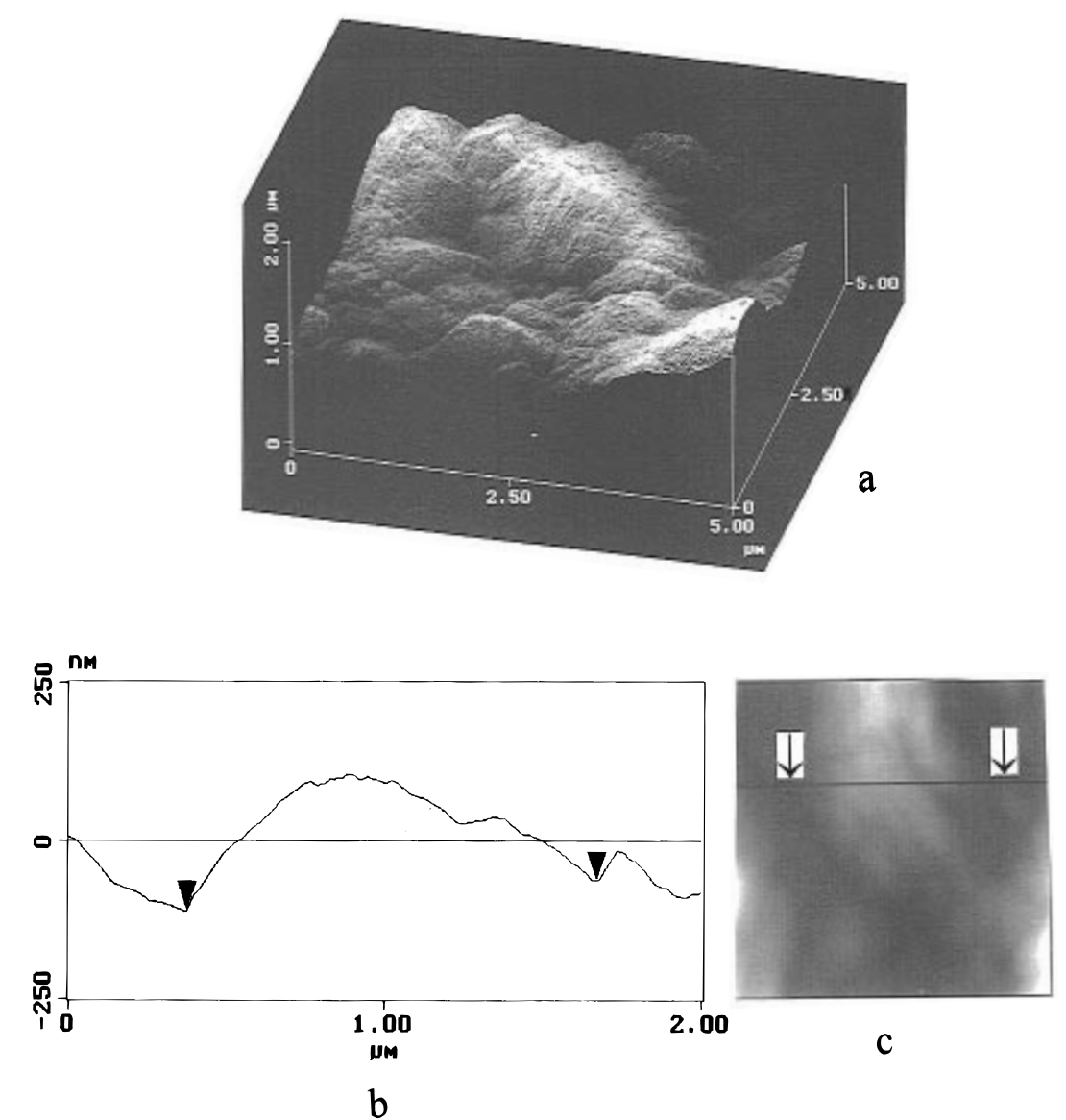

Figure 7. (a) Three-dimensional STM image $\left(5 \times 5 \mu \mathrm{m}^{2}\right)$ of a Ni electrodeposit grown at $j=0.4 \mathrm{~A} \mathrm{~cm}{ }^{-2}\left(q=551 \mathrm{C} \mathrm{cm}^{-2}\right)$. (b) Cross section of a domain $\left(2 \times 2 \mu \mathrm{m}^{2}\right)$ of the STM image shown in part c. The STM image (2D) shown in part c corresponds to a domain of the 3D STM image depicted in part a.

duction to $\mathrm{Ni}_{\mathrm{ad}}{ }^{+}$. The latter probably exists as either $\mathrm{NiOH}_{\text {ad }}$ or $\mathrm{Ni}(\mathrm{OH})_{2}$ depending on the local $\mathrm{pH}$. It should be noted that $\mathrm{Ni}_{\text {ad }}{ }^{+}$has been proposed as a catalyst associated with the propagation of kink sites at the $\mathrm{Ni}$ surface. ${ }^{15,17}$ Reactions 5-7 represent $\mathrm{H}$ sorption processes on the $\mathrm{Ni}$ cathode competing with $\mathrm{Ni}_{\text {ad }}{ }^{+}$for nucleation sites. The presence of $\mathrm{H}_{\mathrm{ad}}$ has been inferred from electrochemical impedance data. ${ }^{17}$ In fact, the above mentioned reaction mechanism can explain the Ni electrodeposition, $\mathrm{H}_{2}$ evolution, and $\mathrm{H}$ absorption into bulk $\mathrm{Ni}$ which occur in the system investigated in this study.

Electrochemical measurements also indicate that the early stages of Ni electrodeposition from Watt's bath are controlled by a nucleation and growth under charge transfer control. ${ }^{2}$ The potentiostatic current transients resulting from this process can be modeled by considering the formation of Ni circular cones with different potentialdependent parallel $\left(k_{1}\right)$ and perpendicular $\left(k_{2}\right)$ growth rates. ${ }^{2}$ However, the linear $j$ vs $E$ relationship observed at high cathodic currents (Figure 1a) suggests that the kinetics of the cathodic reaction is mainly under ohmic control. In principle, this fact would be related to the formation of hydrogen bubbles at the downward-facing working electrode detected during the growth of the $\mathrm{Ni}$ electrodeposition for $E<-0.90 \mathrm{~V}$, which can cause an increase in the effective solution resistivity. However, taking into account that the working electrode is rotated, the deviation of the polarization curve from a Tafel-like behavior can be mainly related to a partial blocking of the active area by the hydrogen bubbles rather than a change in the electrodeposition kinetics. In fact, the compactness

(17) Chassaing, E.; Joussellin, M.; Wiart, R. J. Electroanal. Chem. Interfacial Electrochem. 1981, 157, 75. of Ni deposits observed by STM is consistent with a growth process controlled by an electrochemical reaction at the solid surface. ${ }^{10}$ Therefore, the possibility that Laplacian fields become operative in the growth mode of the deposit can be disregarded because this implies a kinetics leading to deposits with open and ramified structures. ${ }^{9}$

Let us consider the dependence of $\xi$ on $j$ taking into account how the value of $j$ influences the nucleation and growth rate of the $\mathrm{Ni}$ deposit and the rate of production of intermediates during $\mathrm{Ni}^{2+}$ ion discharge. Thus, at low values of $j$, as the nucleation and growth rate is low, a small number of growing nuclei are formed, favoring the formation of large pyramid-like crystals. However, as $j$ is increased, the increase in the nucleation rate leads to the formation of crystals of smaller size. From the preceding growth mode it can be concluded that at large scale lengths the value of $\xi$ is determined by height fluctuations among crystals, and then, the decrease in crystal size results in the decrease of the $\xi$ value. However, this simple picture can be obscured by the change in the relative contribution of reactions $1-7$ as $j$ is increased. In fact, the degree of surface coverage $\left(\theta_{\mathrm{H}}\right)$ by $\mathrm{H}_{\mathrm{ad}}$ produced through reaction $5 \mathrm{~b}$ at steps increases with the applied potential, ${ }^{15}$ and hence, the absorption of hydrogen into $\mathrm{Ni}$ through reaction 7 is assisted, as was observed through hydrogen-charging experiments. It should be noted that $\mathrm{Ni}_{\mathrm{ad}}{ }^{+}$, whose degree of surface coverage $\left(\theta_{\mathrm{Ni}}\right)$ is also potential dependent, ${ }^{16}$ competes with $\mathrm{H}_{\mathrm{ad}}$ for the nucleation and growth sites on the crystal surface.

In general, the electrochemical formation of a new phase implies that adsorbed species are incorporated at growing 

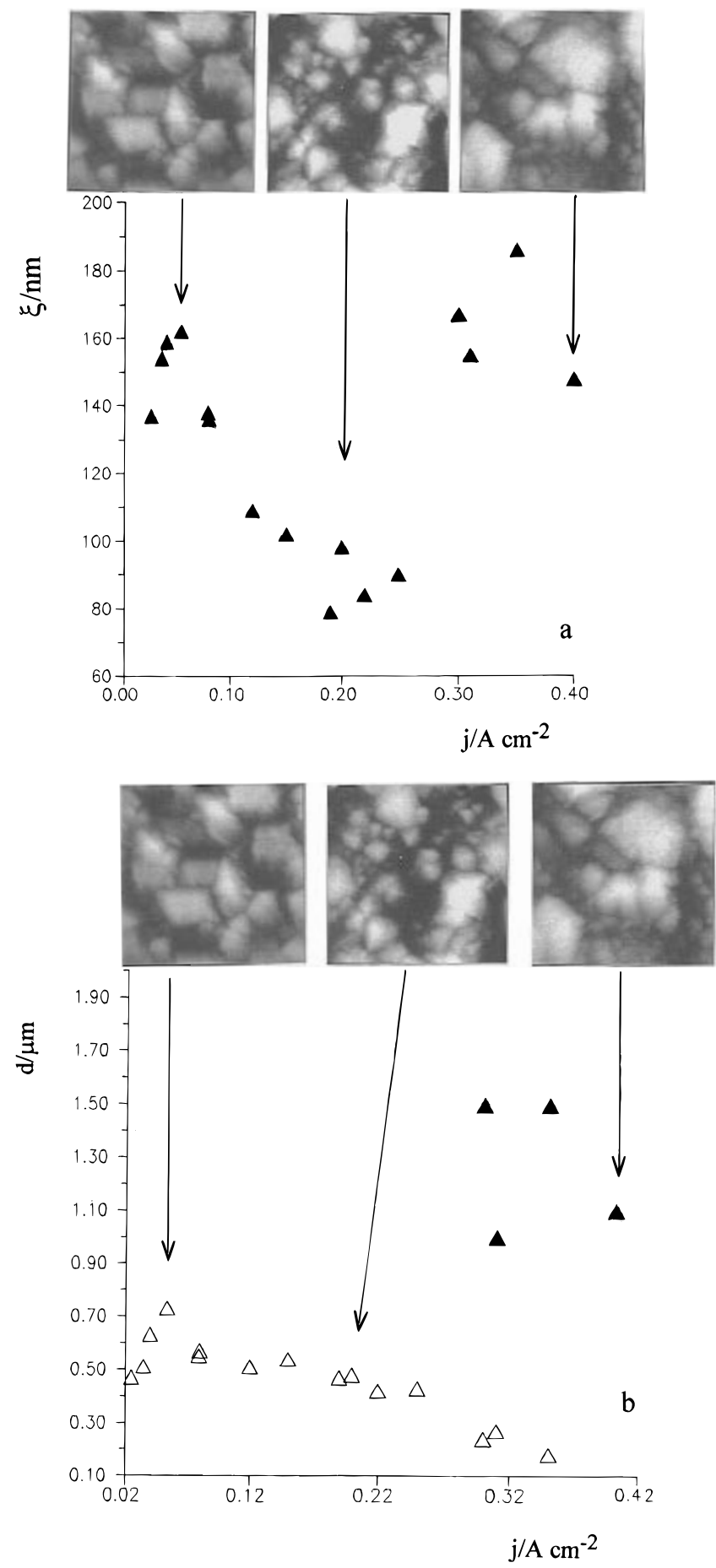

Figure 8. (a) $\xi$ vs $j$ and (b) $d$ vs $j$ plots. Filled circles in (b) correspond to the average size of large crystals. Data derived from STM images. STM images (top view $5 \times 5 \mu \mathrm{m}^{2}$ ) of deposits formed at three values of $j$ as indicated by arrows.

steps, and then into the deposit. ${ }^{18-20}$ Furthermore, strongly adsorbed species such as $\mathrm{H}_{\mathrm{ad}}$ on $\mathrm{Ni}$ at advancing growth steps ${ }^{17}$ tend to inhibit lateral growth and promote vertical growth. Therefore, it is reasonable to admit that on increasing $j$ most available sites at steps are covered by $\mathrm{H}_{\mathrm{ad}}$, the value of $\theta_{\mathrm{H}}$ approaching saturation. In fact, values $\theta_{\mathrm{H}}$ as large as 0.6 have been estimated for $\mathrm{Ni}$ electrodeposition from acid baths. ${ }^{16}$ Under these circum-

(18) Nakahara, S.; Mahajan, S. J. Electrochem. Soc. 1980, 127, 283 (19) Amblard, J.; Epelboin, I.; Froment, M.; Maurin, G. J. Appl. Electrochem. 1979, 9, 233.

(20) Yoshimura, S.; Yoshihara, S.; Shirakashi, T.; Sato, E. Electrochim. Acta 1994, 39, 589.

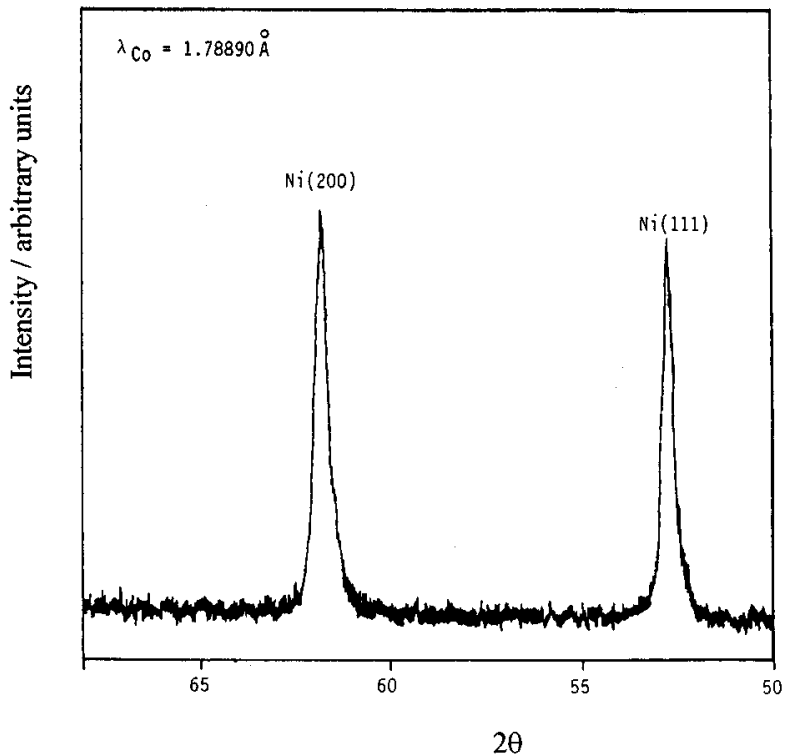

Figure 9. X-ray diffractogram of a Ni electrodeposit grown at $j=0.4 \mathrm{~A} \mathrm{~cm}^{-2}\left(q=551 \mathrm{C} \mathrm{cm}^{-2}\right)$.

stances, further nucleation should proceed at crystal terraces leading to a net predominance of the vertical over lateral growth, i.e. $k_{1} \ll k_{2}$. This transition in the growth mode can also be related to the pyramidal to nodular morphological change which has been described for $\mathrm{Ni}$ electrodeposition. ${ }^{3}$ The appearance of large Ni crystals over a background of the small pyramid-like crystals results in a sudden increase in the value of $\xi$. The preceding discussion can explain the dependence of $\xi$ on $j$ observed for Ni electrodeposition.

4.2. Dynamic Scaling Analysis, Roughness Kinetics, and Mechanism. Further information about the degree of order/disorder at the Ni electrodeposit surface, involving particularly the growth mechanism operative in the $\mathrm{Ni}$ coatings formed at different $j$ values, can be derived from values of $\xi$. For this purpose, the application of the dynamic scaling theory ${ }^{10}$ to STM images becomes particularly useful. ${ }^{9,21,22}$ According to this theory $\xi$ scales as

$$
\xi(L, h) \propto L^{\alpha} f(x)
$$

where $L$ is the sample size, $\alpha$ is the static roughness exponent, and $f(x)=t / L^{\alpha / \beta}, f(x)=$ const for $x \Longrightarrow \infty$, and $f(x)$ $=x^{\beta}$ for $x_{0} \Rightarrow$, being the dynamic roughening exponent. The value of $\xi$ is defined as

$$
\xi(L)=\left[1 / N \sum\left[h\left(x_{i}\right)-\langle h\rangle\right]^{2}\right]^{1 / 2}
$$

where $h\left(x_{i}\right)$ is the deposit height measured along the $x$ direction at the point $x_{i}$, and $\langle h\rangle$ is the average height of the sample formed by $N$ points. For $t \Longrightarrow 0$ eq 8 becomes

$$
\xi \propto t^{\beta}
$$

After a certain critical time or thickness is reached, eq 8 becomes

$$
\xi(L) \propto L^{\alpha}
$$

For fractal surfaces, the value of $\alpha$ which can take values in the range $0<\alpha<1$ characterizes the degree of disorder

(21) Salvarezza, R. C.; Vázquez, L.; Herrasti, P.; Ocón, P.; Vara, J. M.; Arvia, A. J. Europhys. Lett. 1992, 20, 727.

(22) Krim, J.; Indekeu, J. O. Phys. Rev. E 1993, 48, 1576. Meakin, P. Phys. Rep. 1993, 235, 189. 
existing at the deposit surface. For a deposit growth in a three-dimensional space, the value of $\alpha$ is related to $D$, the surface fractal dimension by $D=3-\alpha$. Thus, for $\alpha$ $\Longrightarrow 1$ the surface tends to be euclidean (ordered) and hence, $D \Longrightarrow 2$, whereas for $\alpha \Longrightarrow 0$ the surface exhibits an increasing disorder and $D \Longrightarrow 3$, i.e. the surface tends to fill the overall volume. A detailed discussion of the meaning of $\alpha$ is given in ref 22. Therefore, according to eq $10 \mathrm{~b}$ a $\log \xi$ vs $\log L$ plot can be used to determine the value of $\alpha$ at different j.

In the case of $\mathrm{Ni}$ electrodeposits grown at $j=0.05 \mathrm{~A}$ $\mathrm{cm}^{-2}$, the $\log \xi$ vs $\log L$ plot exhibits a straight line with the slope $\alpha(\mathrm{I})=0.87$ up to $\log L_{1}=2.9$ (Figure 10a). In the range $2.9<\log L<3.5$, the slope results in $\alpha($ II $)=$ 0.5 , and for $L>3.5$ a saturation region is attained. On the other hand, on increasing to $j=0.25 \mathrm{~A} \mathrm{~cm}^{-2}$ a similar plot is found, but the intersection of the two straight line portions decreases to $\log L_{1}=2.7$ so that the portion with the slope $\alpha(\mathrm{II})=0.5$ is more extended, covering almost one decade in $\log L$ (Figure 10b). Finally, for $j>0.3 \mathrm{~A}$ $\mathrm{cm}^{-2}$, only the first straight line portion in the $\log \xi$ vs $\log$ $L$ plot with $\alpha(\mathrm{I})=0.83$ can be seen, and a saturation region appears for $\log L>3.2$ (Figure 10c).

It should be noted that although for computer-simulated surfaces data covering 4-5 orders of magnitude are required for logarithmic fitting; for experimental systems the situation is less ambitious, and log vs log linear plots covering at least 1 order of magnitude or thereabouts are acceptable. ${ }^{23}$

The value of the crossover length $L_{1}$ can be attributed to the average $\mathrm{Ni}$ crystal size, ${ }^{24}$ as results from the comparison of $L_{1}$ with data on $d$ shown in Figure 8b. This means that for $L<L_{1}$ the value of $\alpha$ provides information about the crystal surface, whereas for $L>L_{1}$ it probes the surface properties of a collection of crystals.

The $\log A_{\mathrm{f}}$ vs $\log t$ plot resulting from Figure 2 allows the evaluation of $\beta$ using eq 10a on the assumption that $A_{\mathrm{f}} \propto \xi$ for a rough and compact deposit ${ }^{10}$ as those depicted in Figures 5-7. Thus, for $j=0.3 \mathrm{~A} \mathrm{~cm}^{-2}$ the $\log A_{\mathrm{f}}$ vs $\log$ $t$ plot yields a straight line with the slope $\beta=0.2$ (Figure 11).

The preceding dynamic scaling analysis of STM images of Ni electrodeposits indicates that the surface of pyramidlike crystals grown at low $j$ is characterized by $\alpha(\mathrm{I}) \cong 0.9$, i.e. those crystal surfaces can be described as highly ordered surfaces. This conclusion is only valid inside the large pyramids, as for $L>L_{1}$ a somewhat disordered surface is produced, and hence, $\alpha(\mathrm{II})=0.5$. This disorder arises from height fluctuations among growing pyramids. However, for $j=0.25 \mathrm{~A} \mathrm{~cm}^{-2}$, the pyramid size decreases so that the first linear region in the $\log \xi$ vs $\log L$ plot diminishes, and hence, the second linear region related to pyramid height fluctuations becomes clearly defined.

Finally, for $j>0.25 \mathrm{~A} \mathrm{~cm}^{-2}$, large nodular crystals dominate the surface topography, and only one region with $\alpha(\mathrm{I}) \cong 0.83$ can be observed. In this case, the slight decrease in $\alpha(\mathrm{I})$ as compared to $\alpha(\mathrm{I})=0.87$ for those large crystals produced at $j \cong 0.05 \mathrm{~A} \mathrm{~cm}^{-2}$ should be related to the presence of a large number of bumps which introduce some noise into the surface. Therefore, the increase from $j=0.05 \mathrm{~A} \mathrm{~cm}^{-2}$ to $j=0.25 \mathrm{~A} \mathrm{~cm}^{-2}$ causes a smooth increase in the degree of surface disorder due to the decrease in crystal size and the greater relevance of small height fluctuations among pyramid-like crystals. However, for $j>0.25 \mathrm{~A} \mathrm{~cm}^{-2}$ the surface topography is dominated by a new type of large crystals with some noise related to the

(23) Vázquez, L.; Salvarezza, R. C.; Herrasti, P.; Ocón, P.; Vara, J. M.; Arvia, A. J. Appl. Surf. Sci. 1993, 70/71, 413.

(24) Herrasti, P.; Ocón, P.; Vázquez, L.; Salvarezza, R. C.; Vara, J. M.; Arvia, A. J. Phys. Rev. A 1992, 45, 7440.
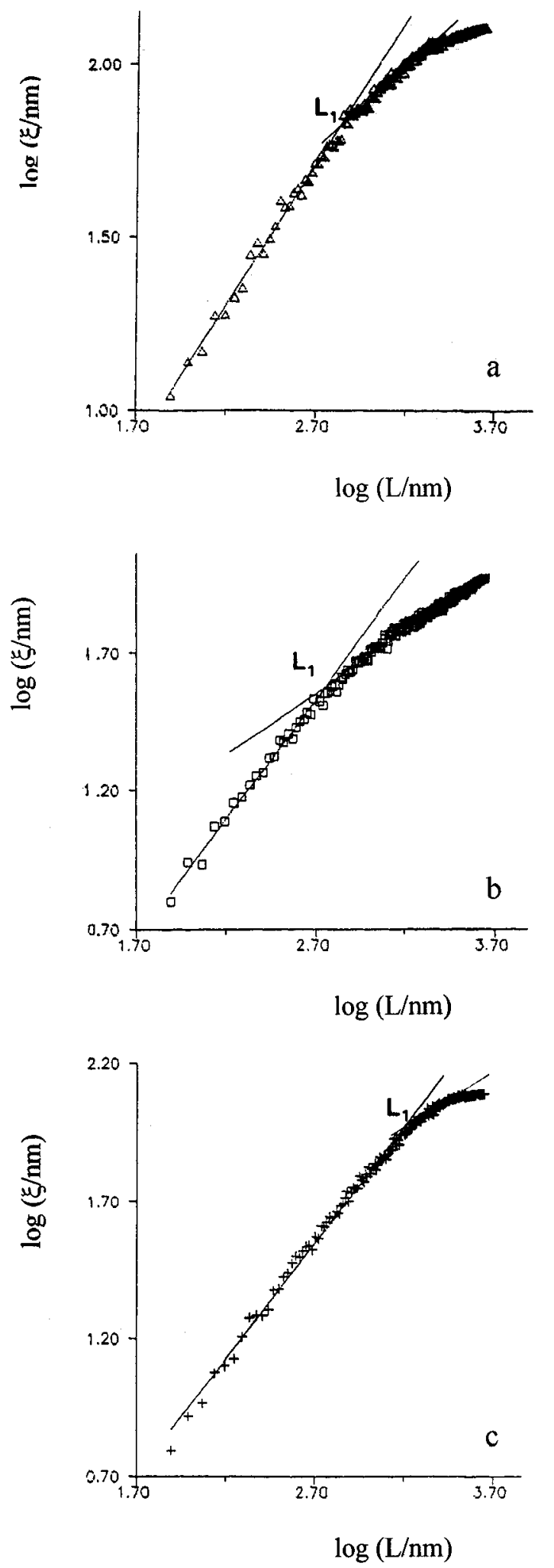

Figure 10. $\log \xi$ vs $\log L$ plots for Ni electrodeposits grown at different values of $j$ : (a) $j=0.05 \mathrm{~A} \mathrm{~cm}^{-2}$, (b) $j=0.25 \mathrm{~A} \mathrm{~cm}^{-2}$, (c) $j=0.4 \mathrm{~A} \mathrm{~cm}^{-2}$.

bumps themselves. Accordingly, the "smooth" to "rough" transition observed at $j \cong 0.25 \mathrm{~A} \mathrm{~cm}^{-2}$ is equivalent to "a strongly disordered" to "a weakly disordered" transition for $L>d$.

Experimental values of $\alpha$ and $\beta$ can be used to test the validity of different growth models for Ni electrodeposition on $\alpha$-brass. Values of $\alpha$ and $\beta$ predicted by models based on thermodynamic considerations such as the layer by 


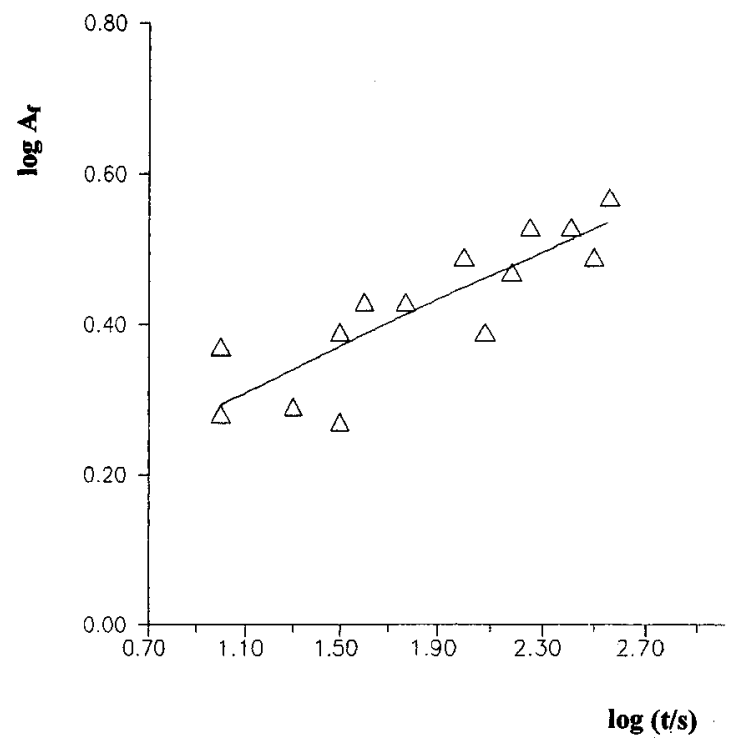

Figure 11. $\log A_{\mathrm{f}}$ vs $\log t$ plot derived from data shown in Figure 2b.

layer growth (Frank-van der Merwe model, FM), ${ }^{25}$ the initial nucleation and 3D growth (Volmer-Weber model, VW),${ }^{26}$ and the initial formation of a monolayer followed by $3 \mathrm{D}$ growth (Stranski-Krastanov model, SK) ${ }^{27}$ should be considered first. Thus, the FM model leads to "effective exponents" $\alpha=0$ and $\beta=0$, whereas the VW and SK models lead initially to values of $\alpha$ in the range $0.5<\alpha$ $<0.6$ and a time-dependent value of $\beta .{ }^{11}$ The VW and SK models also predict that when 3D nuclei tend to overlap the topography switches over to the FM behavior. ${ }^{11}$ It is worth emphasizing that the values of $\alpha$ and $\beta$ resulting from thermodynamic models are not true scaling exponents. Note that for the FM model the value $\alpha=0$ only indicates that $\xi$ becomes independent of $L$, and in this case no information about order/disorder can be inferred. In fact, the layer by layer growth model yields a highly ordered surface.

On the other hand, nonequilibrium growth models introduce kinetic limitations into the FM model. ${ }^{10}$ Nonequilibrium models contain a roughening term $\eta$, which represents the white noise in the flux of incoming particles. In general, these models can be described by the continuous Kardar-Parisi and Zhang (KPZ) stochastic equation for the interface motion ${ }^{28}$ which in 3D space leads to $\alpha=$ 0.4 and $\beta=0.25$. When surface diffusion of the incoming particles is incorporated into the growth process, the interface evolution results from a competition between the roughening and the smoothening term produced by the mobility of arriving particles. In this case, different models have been proposed, such as the Wolf-Villain $(\mathrm{WV})^{29}$ which predicts $\alpha=1$ and $\beta=0.25$, the Lai-Das Sarma (LDS) leading to $\alpha=0.66$ and $\beta=0.20,{ }^{30}$ and the Siegert-Plischke (SP) providing $\alpha=1$ and $\beta=0.25,{ }^{31}$ all for a 3D growth.

Experimental values $\alpha(\mathrm{I}) \cong 0.9$ and $\beta=0.2$ for the surfaces grown at $j>0.25 \mathrm{~A} \mathrm{~cm}^{-2}$ are close to those expected for WV and SP models. However, the first model

(25) Frank, F. C.; van der Merwe, J. H. Proc. R. Soc. London, Ser. A 1949, 198, 205

(26) Volmer, M.; Weber, A. Z. Phys. Chem. 1926, 119, 277.

(27) Stranski, J. N.; Krastanov, L. Akad. Wiss. Math. Nat. K 1938 $111 b, 797$. 889.

(28) Kardar, M.; Parisi, G.; Zhang, Y. C. Phys. Rev. Lett. 1986, 56 ,

(29) Wolf, D. E.; Villain, J. Europhys. Lett. 1990, 13, 389. Villain, J. J. Phys. 1992, I1, 19.

(30) Lai, Z. W.; Das Sarma, S. Phys. Rev. Lett. 1991, 66, 2348.

(31) Siegert, M.; Plischke, M. Phys. Rev. Lett. 1994, 74, 1517.
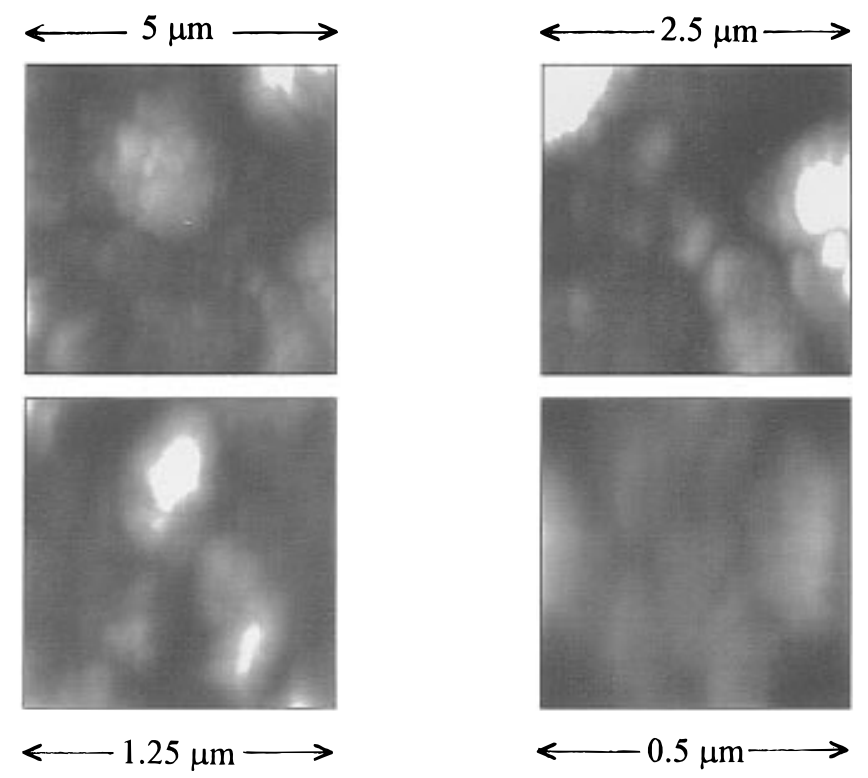

Figure 12. STM images (top view) of a Ni electrodeposit taken at a different resolution. The presence of nodular elements at all scales can be observed.
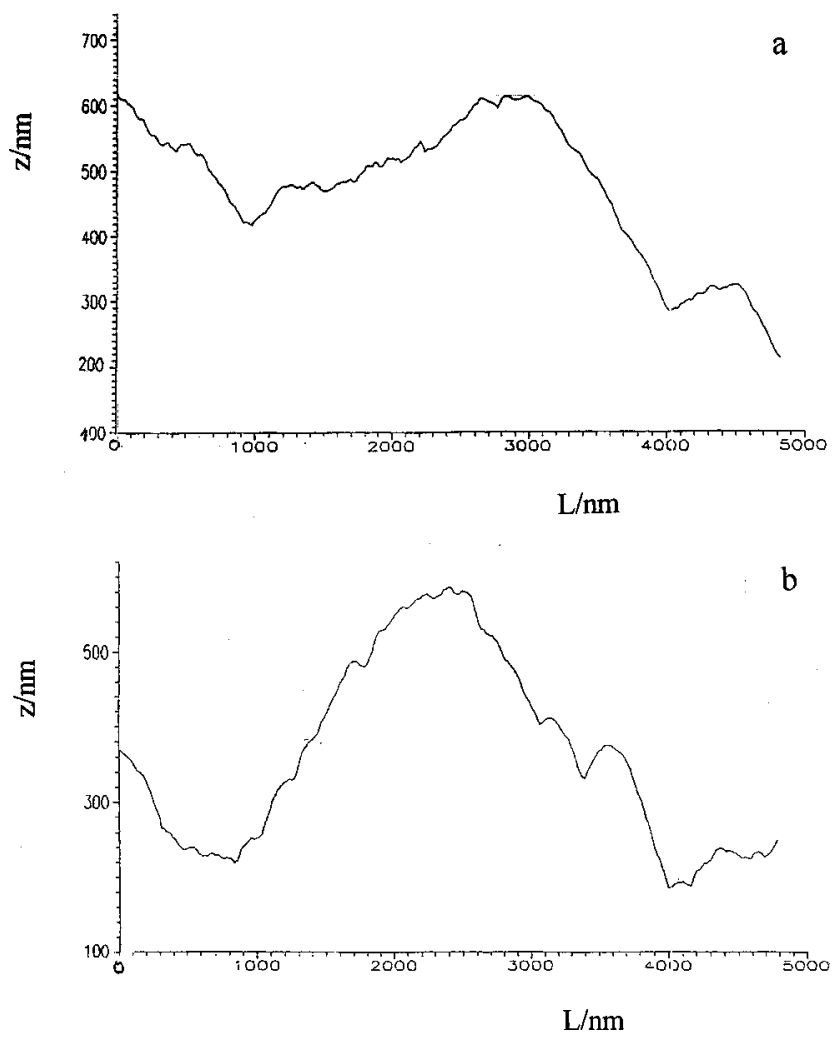

Figure 13. Cross sections resulting from STM images of $\mathrm{Ni}$ deposits grown at (a) $j=0.25 \mathrm{~A} \mathrm{~cm}^{-2}$ and (b) $j=0.4 \mathrm{~A} \mathrm{~cm}^{-2}$. The self-affine character of these profiles can be observed.

yields a self-affine fractal surface, whereas the second leads to smooth pyramids which behave as euclidean objects. Therefore, in the SP model $\alpha$ and $\beta$ are as in those models based on thermodynamics, really "effective exponents" rather than true scaling exponents. The STM images taken at different resolutions (Figure 12) and the cross section of the Ni electrodeposits (Figure 13) grown at high $j$, however, seem to indicate that the surface is better described as a self-affine fractal rather than a euclidean surface. From the experimental point of view, values of $\alpha \cong 1$ have been obtained for vapor-deposited ${ }^{19,32}$ 
and electrodeposited $\mathrm{Au}^{33}$ films for $L<d$ where surface diffusion is expected to play a relevant role.

Surface diffusion of $\mathrm{Ni}$ atoms in Watt's bath may contribute to the deposit topography due to the high $\mathrm{Cl}^{-}$ concentration in the bath and the working temperature, $60{ }^{\circ} \mathrm{C}$. It has been reported that both the presence of $\mathrm{Cl}^{-}$ ions and temperature promote surface diffusion of metal atoms in aqueous environments. ${ }^{34-39}$

On the other hand, the value $\alpha(\mathrm{II})=0.5$, which can be observed for those samples grown at $j<0.25 \mathrm{~A} \mathrm{~cm}^{-2}$ for $L>L_{1}$, has been already reported for Au electrodeposits grown at high overvoltages. ${ }^{33}$ However, as none of the present growth models involve the influence of crystal growth competition on the topography of the deposit, the theoretical meaning of $\alpha(\mathrm{II})=0.5$ is still unclear.

\section{Conclusions}

(1) In the range of low current density, the kinetics of $\mathrm{Ni}$ electrodeposition on $\beta$-brass from Watt's bath are controlled by a surface process involving the first charge

(32) Vázquez, L.; Salvarezza, R. C.; Herrasti, P.; Ocón, P.; Vara, J. M.; Arvia, A. J. Chaos, Solitons and Fractals 1995, 6, 569.

(33) Vázquez, L.; Salvarezza, R. C.; Ocón, P.; Herrasti, P.; Vara, J. M.; Arvia, A. J. Phys. Rev. E 1994, 49, 1507.

(34) Vela, M. E.; Zubimendi, J. L.; Salvarezza, R. C.; Vázquez, L.; Vara, J. M.; Arvia, A. J. Langmuir, in press.

(35) Bonzel, H. P. In Surface Physics of Materials; Blakely, J. M., Ed.; Academic Press: New York, 1975; p 280 and references therein. (36) Trevor, D. J.; Chidsey, C. E. D.; Loiacono, D. N. Phys. Rev. Lett. 1989, $62,929$.

(37) Alonso, C.; Salvarezza, R. C.; Vara, J. M.; Arvia, A. J. Electrochim. Acta 1990, 35, 1331.

(38) Gómez-Rodríguez, J. M.; Vázquez, L.; Baró, A.; Salvarezza, R C.; Vara, J. M.; Arvia, A. J. J. Phys. Chem. 1992, 96, 347.

(39) García, M. P.; Gómez, M. M.; Salvarezza, R. C.; Arvia, A. J. J. Electroanal. Chem. 1993, 347, 237. transfer reaction to $\mathrm{Ni}^{2+}$ ion yielding $\mathrm{Ni}^{+}$adsorbed species. In the range of high current density, the kinetics of $\mathrm{Ni}$ electrodeposition are complicated by the formation of hydrogen bubbles and hydrogen penetration into the $\mathrm{Ni}$ coatings.

(2) The topography of the Ni coatings changes from rough to smooth and becomes rough again as the current density is increased. The smooth to rough transition is related to the appearance of the nodular structure, and it is promoted by adsorbed hydrogen which hinders lateral growth.

(3) Ni coatings can be described as self-affine fractals rather than euclidean objects or self-similar fractals. For $L>d$, the topographic changes with current density from rough to smooth and from smooth to rough are equivalent to changes in the electrodeposit surface from an ordered to a disordered surface and from a disordered to an ordered surface, respectively.

(4) In the range of high current density, values of the roughening exponents $\alpha$ and $\beta$ resulting from the dynamic scaling analysis of STM images are consistent with those expected from aggregation models with a significant contribution of surface atom diffusion.

(5) From a discussion coordinating kinetic and roughness analysis data, it is possible to discriminate the relative contributions of different rate processes to the growth of $\mathrm{Ni}$ coatings on $\beta$-brass from Watt's bath.

Acknowledgment. Financial support for this work by Dirección General de Universidades e Investigación (DGICYT-Spain) project PB 93/0564 is gratefully acknowledged. R.C.S. and A.J.A. also thank DGICYT (Spain).

LA9505780 